\title{
Trabalho em Marx e Serviço Social
}

The Work on Marx and Social Work

\section{Evaristo Colmán* Karina Dala Pola**}

\section{Resumo:}

Este artigo apresenta algumas notas acerca da categoria trabalho tal como era analisada por Karl Marx, com a intenção de reforçar a compreensão que temos de que o Serviço Social é trabalho.

PALAVRAS CHAVE: Trabalho; Serviço Social e trabalho.

\begin{abstract}
:
Using Karl Marx's approach, this article addresses some issues related to the work category, and it seeks to strengthen our current understanding of Social Work as equivalent to work.
\end{abstract}

Key words: Work; Social Work.

\section{Introdução}

No debate inaugurado por Sergio Lessa ao negar que o Serviço Social seja trabalho a argumentação dos autores busca sua legitimação na letra de Marx. Apresentamos, nas notas a seguir, algumas das formulações de Marx acerca da categoria trabalho como Marx a entendia e analisava, com a intenção de avançar na afirmação de que o Serviço Social é trabalho.

\section{Trabalho em Geral e Trabalho Historicamente Determinado}

Inicialmente, Marx caracteriza o trabalho como uma interação do homem com o mundo natural, de tal modo que os elementos deste último são conscientemente

\footnotetext{
* Assistente Social/PUC-SP, doutor em História pela UNESP e docente do Curso de Serviço Social da UEL Email: colman@uel.br.

** Assistente Social/UEL, Mestre em Serviço Social pela UEL. E-mail dala_pola@yahoo.com.br.
} 
modificados para alcançar um determinado propósito. O trabalho é a forma pela qual o homem se apropria da natureza a fim de satisfazer suas necessidades.

No processo de trabalho a atividade humana é materializada ou objetivada em valores de uso. "O processo de trabalho, como o apresentamos em seus elementos simples e abstratos, é atividade orientada a um fim para produzir valores de uso, apropriação do natural para satisfazer a necessidades humanas [...]" (MARX,1985a, p.153).

Os meios de produção constituem-se dos objetos de trabalho e dos meios de trabalho. Os meios de trabalho incluem tanto os elementos que são precondições essenciais para o funcionamento do processo de trabalho, embora com ele se relacionem indiretamente (canais, estradas, entre outros), quanto os elementos através dos quais o trabalho se exerce sobre seu objeto, como as ferramentas e as máquinas. Esses últimos são sempre resultado de processos de trabalho anteriores, e seu caráter está relacionado ao grau de desenvolvimento do trabalho e às relações sociais sob as quais é realizado. Matéria-prima é aquilo que é usado no processo de trabalho e que já é resultado de um trabalho realizado anteriormente. Os objetos de trabalho que não tem trabalho anterior não são matéria-prima, são brutas.

O trabalho, nos seus elementos simples, é aquele produtor de valores de uso, pois.

[...] a existência [...] de cada elemento da riqueza material não existente na natureza, sempre teve de ser mediada por uma atividade especial produtiva, adequada a seu fim, que assimila elementos específicos da natureza a necessidades humanas específicas. Como criador de valores de uso, como trabalho útil, é o trabalho, por isso, uma condição de existência do homem, independente de todas as formas de sociedade, eterna necessidade natural de mediação do metabolismo entre homem e natureza e, portanto, da vida humana (MARX, 1985a, p.50).

Marx caracteriza o trabalho, de um ponto de vista mais geral, como a interação entre o homem e a natureza, com o objetivo de transformar a natureza nos bens necessários à sobrevivência do homem. 
Deste ponto de vista, só seria trabalho a atividade que promovesse esta interação e consequentemente somente seria trabalho produtivo o que resultasse em um produto1. Esta é uma primeira determinação do trabalho em Marx. Contudo o autor já faz uma ressalva, na qual afirma que "Essa determinação de trabalho produtivo, tal como resulta do ponto de vista do processo simples do trabalho, não basta de modo algum, para o processo de produção capitalista" (MARX, 1985a, p.151). Aqui Marx já contrapõe o trabalho do ponto de vista do processo simples ao modo como deve ser apreciado do ponto de vista específico da produção capitalista, ou seja, de um ponto de vista historicamente determinado.

Desta forma, quando se discute a questão da produção, é preciso situar historicamente a que modo de produção se está fazendo referência, delimitando, assim, o nível do desenvolvimento social, pois cada formação econômica (escravista, feudal, capitalista) tem diferentes relações de produção e é justamente isso que as distingue.

Posto isso, devemos entender que a análise do trabalho, feita por Marx no capitalismo, parte da categoria valor. Ou seja, o trabalho deve ser analisado sob o aspecto social, junto com a forma valor, pois, ele é a substância do valor2. Desta forma, o objeto de investigação de Marx é o valor enquanto forma social do produto do trabalho.

Assim, o trabalho não pode ser analisado somente segundo aspectos técnicos, pelo seu conteúdo material, mas, deve ser analisado segundo sua forma social históricoconcreta. Isso não significa que Marx, ao realizar seus estudos, tenha ignorado o grau de desenvolvimento das forças produtivas, pelo contrário. Ele busca desvendar o segredo do modo capitalista de produção que muitas vezes fica oculto sob o deslumbrante desenvolvimento das forças produtivas.

O desenvolvimento do modo produção especificamente capitalista exige, como condição prévia, a separação entre o trabalho e os meios de produção, de forma que o proprietário do trabalho, ou para ser mais exato, da força de trabalho, se veja obrigado a vendê-la ao proprietário dos meios de produção em troca de um salário. Isto ocorre

\footnotetext{
1 "considerando-se o processo inteiro do ponto de vista de seu resultado, do produto, aparecem ambos, meio e objeto de trabalho, como meios de produção, e o trabalho mesmo como trabalho produtivo." (MARX, 1985a, p.151)

2 "Tempo de trabalho socialmente necessário é aquele requerido para produzir um valor de uso qualquer, nas condições dadas de produção socialmente normais, e com o grau social médio de habilidade e de intensidade do trabalho" (Marx, 1985a, p. 48).
} 
porque o trabalhador direto - o verdadeiro e genuíno produtor - foi expropriado previamente de toda propriedade e vê-se obrigado, para sobreviver, a vender a única coisa de que dispõe: sua força de trabalho, tornando-se assim um trabalhador assalariado.

A força de trabalho comprada será incorporada ao capital no processo da produção, valorizando o capital inicial, ou seja, produzindo mais-valia. A parte do capital que se transforma em salários é chamada de capital variável porque só a mercadoria força de trabalho produz um valor maior do que custa ao capitalista. A mais-valia parece ser uma simples consequência do processo de produção, mas é muito mais, é o motor de todo este processo, sem a mais-valia não haveria o processo nem relações de produção capitalistas. Todo o interesse do capital está concentrado nela. Por isso, no modo de produção capitalista, só é considerado produtivo o trabalho assalariado que, de uma maneira ou de outra, produz mais-valia.

\section{O Trabalho no Capitalismo}

Como já foi dito acima, em um primeiro momento, Marx, na sua crítica à economia política, apresenta o processo de trabalho somente em seus elementos simples e abstratos (atividade orientada a um fim, objeto de trabalho e instrumento de trabalho), ou seja, como eterna condição natural da vida humana e, por isso, independente de qualquer forma de organização social. Todavia, no sistema capitalista, estes elementos do processo de trabalho já não são suficientes para explicar o domínio do homem sobre a natureza, pois este se transforma em um processo social de produção, deixando de ser um processo individual entre o homem e a natureza.

Assim, o trabalho não deve ser analisado apenas pelas suas diferentes formas e/ou pelo seu aspecto técnico, mas é preciso levar em conta as relações sociais nas quais ocorre.

Marx analisa as diferentes formas econômicas e sociais em que o trabalho ocorre, e afirma que as relações de produção se desenvolvem em certas condições técnicas e materiais, mas não podem ser confundidas com elas. Esta é, sem dúvida, a grande contribuição de Marx, a de demonstrar a historicidade das formas sociais e como o 
processo de produção técnico e material se dá em um dado nível de desenvolvimento das forças produtivas (RUBIN, 1980).

Antes das sociedades serem divididas em classes sociais a divisão do trabalho era natural, baseada na idade e no sexo dos integrantes da comunidade, no entanto, sob o sistema capitalista, tal divisão adquire uma base social, homens, mulheres e crianças passam a serem vistos como um todo homogêneo e indiferenciado.

Nas sociedades sem classes o homem estava organicamente ligado à natureza. Naquelas sociedades, a produção estava voltada apenas para a produção de valores de uso, ou seja, a satisfação das necessidades da comunidade. Na sociedade capitalista o objetivo passa a ser a produção de valores de troca, ou seja, a produção, a reprodução e a valorização do capital (SCHMIDT, 1976).

O desenvolvimento do capital pressupõe algumas condições históricas, por um lado o trabalhador livre que permita o intercambio da sua força de trabalho por dinheiro, para que o capital possa se reproduzir e valorizar, e por outro a separação do homem dos meios necessários para sua reprodução material.

Na relação entre o trabalho assalariado e o capital, o produtor é alijado dos meios de produção necessários a sua reprodução, e precisa vender sua força de trabalho a fim de se reproduzir. "Todo o sistema de produção capitalista repousa no fato de que o trabalhador vende e sua força de trabalho como mercadoria" (MARX, 1985c, p.48).

No capitalismo, o trabalhador é reduzido a mero produtor de valor de troca, o que implica a negação de sua existência natural, ou seja, significa afirmar que o trabalhador e, consequentemente, a sua produção estão determinados totalmente pela sociedade.

[...] en la producción capitalista el trabajador es literalmente desnaturalizado al transformarse en 'capacidad laboral puramente subjetiva, privada de objetividad', la cual ve su negación en los presupuestos materiales, extrañados por ella, del trabajo 'como valor existente para sí. El trabajador ya no es para el capital ni siquiera condición de la producción sino depositario de trabajo, que es apropiado a través del intercambio (SCHMIDT, 1976, p.205).

A economia capitalista representa a totalidade das relações de produção entre as pessoas, ou seja, a união do processo técnico material com suas formas sociais. Não podemos entender o modo de produção capitalista descolado das relações de produção entre as pessoas. A vida social, política e intelectual é condicionada pelo modo de 
produção da vida material, da mesma forma, a consciência do homem é determinada pelo seu ser social, pela forma de organização social na qual o individuo vive. Todo o mundo no qual o homem vive é um produto histórico, mediado pelo trabalho.

Mas, o trabalho, de acordo com a perspectiva marxista, está subordinado, no sistema capitalista, ao propósito de reproduzir e expandir o domínio material e político da classe capitalista, enquanto a maioria da população está separada dos meios de produção e de subsistência e, por conseguinte, é compelida a ingressar no trabalho assalariado a fim de sobreviver.

Um dado período da história da sociedade só pode ser conhecido por meio do modo de produção da vida material. O processo de produção capitalista é a reprodução das condições materiais e das relações sociais que sustentam o sistema capitalista, assim a produção molda o consumo, ou seja, produz os próprios consumidores, o tipo de consumidores. Como diz Marx é:

[...] tanto um processo de produção das condições materiais de existência da vida humana, quanto um processo que se desenvolve através de relações especificas, histórico-econômicas, de produção, o conjunto dessas mesmas relações de produção e, portanto, o processo que produz e reproduz os expoentes deste processo, suas condições materiais de existência e suas mútuas relações, isto é, sua forma econômica determinada de sociedade (apud RUBIN, 1980, p. 27).

Para o desenvolvimento do capitalismo é preciso que existam indivíduos livres, detentores de sua força de trabalho na forma de mercadoria e despossuídos dos meios necessários para a concretização desta força de trabalho. Como estão destituídos dos meios de trabalho, não podem realizar sua própria força de trabalho, por isso, precisam vendê-la no mercado de trabalho, a fim de conseguir concretizá-la, único recurso para garantir sua sobrevivência.

No sistema capitalista, o trabalho privado só interessa ao produtor na medida em que pode ser permutado por outro trabalho útil, como diz Marx "Para ser mercadoria o produto não pode ser produzido como meio de subsistência imediato para seu próprio produtor" (MARX, 1985a, p.140).

Por outro lado, o que permite a troca entre os diferentes trabalhos é a abstração do trabalho concreto, a partir do qual o trabalho é entendido enquanto dispêndio de força de trabalho humana, como trabalho humano indiferenciado, o que importa já não é mais 
o trabalho concreto e sua utilidade, importa somente o trabalho tido na sua forma abstrata, enquanto trabalho indiferenciado, abstrato, geral. O trabalho pode ser equiparado, pois é abstraído de seu caráter concreto específico, torna-se trabalho humano em geral, indiferenciado, abstrato.

Assim, o trabalho que é uma categoria social, no capitalismo tem essa condição obscurecida, dando a impressão de que o trabalho só se torna social na troca, ou que apenas os produtos do trabalho é que são "sociais". O fetichismo da mercadoria significa que este caráter social do trabalho não é transparente. No capitalismo, esta relação é obscurecida, o trabalho não aparece às pessoas como social, o caráter social do trabalho das pessoas aparece no valor. Desta forma, o caráter social dos seus trabalhos adota a forma da igualdade de trabalho no valor, é este o fetichismo da mercadoria, o "quiproquó", nas palavras de Marx. O trabalho é social, porque é produzido não para consumo individual do seu produtor, mas para a venda, é produzido para outros. É na troca que o valor se manifesta.

$\mathrm{Na}$ forma mercadoria, aquilo que é relação social entre os produtores, aparece como relação social entre os produtos do trabalho, ocorre uma inversão nas relações sociais.

O misterioso da forma mercadoria consiste, portanto, simplesmente no fato de que ela reflete aos homens as características sociais do seu próprio trabalho como características objetivas dos próprios produtos de trabalho, como propriedades naturais dessas coisas e, por isso, também reflete a relação social dos produtores com o trabalho total como uma relação social existente fora deles, entre objetos (MARX, 1985a, p.71).

Isso é justamente a forma fetichista da mercadoria. A forma valor, que nada tem a ver com os aspectos ou características físicas das coisas, aparece, no entanto, como atributo das coisas e não como algo inteiramente determinado pela relação social.

Na sociedade escravista e na feudal, o trabalho também já era social, a diferença destas sociedades com a capitalista, é que naquelas sociedades a relação era clara, os produtores tinham consciência de que parte do que produziam era apropriado por outro. O escravo e o servo sabiam claramente qual parcela do seu trabalho destinava-se ao dono de escravos e ao senhor feudal, e aquilo que ficava para eles, diferentemente do 
capitalismo em que esta relação não é transparente, pois o assalariado não tem clareza do quanto produz para si, e do quanto é apropriado pelo capitalista.

Os trabalhos determinados dos indivíduos em sua forma natural, a particularidade, e não a generalidade do trabalho, isto é que constitui neste caso o vínculo social. [...] O trabalho que se apresenta no valor de troca é pressuposto como trabalho do indivíduo particularizado e se torna social assumindo a forma do seu oposto direto: a forma da generalidade abstrata (MARX, 1974, p.146).

Trabalho concreto é o produtor de valores de uso, enquanto o trabalho presente no valor de troca é trabalho social, abstrato e geral, no qual é eliminado o caráter individual do trabalho. Essa é forma que o trabalho assume no sistema capitalista3.

\begin{abstract}
Como atividade que visa, de uma forma ou de outra, à apropriação do que é natural, o trabalho é condição natural da existência humana, uma condição do metabolismo entre homem e natureza, independentemente de qualquer forma social. Ao contrário, trabalho que põe valor de troca, é uma forma especificamente social do trabalho (MARX, 1974, p.148).
\end{abstract}

O trabalho abstrato é trabalho humano indiferenciado, é gasto de força de trabalho do homem independente da forma útil do trabalho, capaz de gerar valor. "[...] atividade produtivas qualitativamente diferentes, são ambas dispêndio produtivo de cérebro, músculos, nervos, mãos etc. humanos, e nesse sentido são ambas trabalho humano" (MARX, 1985a, p.51).

O valor é algo inteiramente social, assim como, o trabalho que dá origem ao valor é trabalho social, ou seja, um resultado histórico. Por isso podemos afirmar que não há uma forma de trabalho imutável, independente da sociedade. O que não significa negar que o trabalho seja indispensável à sociedade, apenas que sua forma muda historicamente.

No capítulo V do livro I de O Capital4, Marx inicia analisando o processo de trabalho sem considerar a forma social na qual o trabalho se dá, diz que "[...] o trabalho é um

\footnotetext{
${ }^{3}$ Lessa parece não considerar a forma específica que o trabalho assume na sociedade capitalista. Considera trabalho somente aquilo que se materializa em alguma coisa palpável, não aceitando que no capitalismo algo pode ter um valor de uso, uma utilidade sem necessariamente resultar em uma coisa separável do seu produtor, como é o caso dos serviços, que possuem valor de uso, mas sua utilidade é inseparável do seu produtor.
} 
processo entre o homem e a natureza, um processo em que o homem, por sua própria ação, media, regula e controla seu metabolismo com a Natureza" (MARX, 1985a, p.149). Entretanto, o trabalho em Marx não é só aquela atividade que promove a transformação da natureza, mas é uma atividade previamente idealizada que promove a transformação do próprio homem. Afirmação que, facilmente, pode ser comprovada pelas próprias palavras do autor.

\begin{abstract}
Uma aranha executa operações semelhantes às do tecelão, e a abelha envergonha mais de um arquiteto humano com a construção dos favos de suas colméias. Mas o que distingue, de antemão, o pior arquiteto da melhor abelha é que ele construiu o favo em sua cabeça, antes de construí-lo em cera. No fim do processo de trabalho obtém-se um resultado que já no início deste existiu na imaginação do trabalhador e, portanto, idealmente (MARX, 1985a, p.149-150).
\end{abstract}

Podemos concluir desta passagem que não basta transformar a natureza, é preciso projetar idealmente tal transformação da natureza. Todos os animais podem transformar a natureza e, de fato, a transformam, mas nem por isso podemos afirmar que eles exerçam qualquer atividade que possa ser chamada de trabalho. Com a divisão do trabalho nas sociedades divididas em classes, começa a fragmentação do trabalho em manual e intelectual (idealização). E se, a partir disso, afirmarmos que só o trabalho manual é trabalho no sentido preciso do termo poderíamos também concluir o absurdo de que a abelha, ao construir seu favo, trabalha afirmação esta que contraria a concepção de Marx, a todos os seus escritos, sejam eles da juventude ou da maturidade.

O animal também promove a transformação da natureza para satisfazer suas necessidades, mas o homem transforma a natureza para satisfazer necessidades socialmente determinadas e de forma previamente idealizada. A práxis dos seres humanos é previamente determinada de forma consciente, é justamente isso que diferencia a práxis humana. O homem cria suas próprias necessidades, mesmo a necessidade de alimentação é socialmente condicionada no homem (VÁZQUEZ, 2007).

\footnotetext{
${ }^{4}$ MARX, K. O Capital: crítica da economia política. Tradução por Regis Barbosa e Flávio R. Kothe. São Paulo: Abril Cultural, 1985a. Livro 1, v.1, t.1. (Os economistas).
} 


\section{O Valor}

Analisaremos a questão do valor inicialmente a partir da mercadoria que, como já dissemos, possui um duplo caráter, valor de uso e valor de troca. O valor de uso de um objeto provém de suas qualidades matérias, de sua utilidade manifesta-se justamente no uso, confunde-se com sua existência, ou seja, pode se dizer que a coisa é um valor de uso. O valor de uso, portanto não expressa necessariamente uma relação social, como claramente afirma Marx "Ainda que o valor de uso seja objeto de necessidades sociais e se articule, por conseguinte, à sociedade, não expressa, todavia, uma relação de produção social" (MARX, 2008, p.50). O valor de troca já representa um determinado modo de produção social. Assim, o valor de uso não é necessariamente uma mercadoria, nem todas as coisas são mercadorias, podem ser apenas valores de uso.

O valor de uso de uma mercadoria é, desta forma, a expressão material do valor de troca, é o trabalho objetivado, visto que, em todas as mercadorias está cristalizado trabalho social. Assim, é este o elemento em comum que possibilita a troca entre as mercadorias, que permite que mercadorias das mais variadas natureza possam ser permutáveis umas pelas outras, pois todas contêm trabalho social, trabalho simples, indiferenciadas, ao qual é indiferente a forma que assume, permitindo equiparar todas as mercadorias. "Sendo indiferente frente à matéria particular dos valores de uso, o trabalho que põe o valor de troca é, por isso, indiferente frente à forma particular do próprio trabalho" (MARX, 1974, p.142-143).

Vimos que o valor de uso é a base material em que se expressa o valor de troca, enquanto o valor de troca é o que permite que os valores de uso possam ser trocados, para isso, em alguma proporção, precisam representar a mesma magnitude de valor. Valor este que é determinado pelo tempo trabalho socialmente necessário, aqui já não importa os diversos tipos de trabalho, mas tão somente a magnitude desses trabalhos expresso no valor de troca, que possibilita a permutabilidade entre as mercadorias.

Esta indiferença em relação ao valor de uso das mercadorias pressupõe uma indiferença em relação ao conteúdo do trabalho realizado, que passa a importar enquanto trabalho humano em geral, trabalho homogêneo. "Graças a essa equivalência, na qual está eliminada a diferença qualitativa de seu valor de uso, aqueles produtos representam um mesmo volume de trabalho idêntico" (MARX, 2008, p.52). Aqui a forma 
específica do trabalho já não é mais relevante, o que importa é justamente o trabalho homogêneo, dispêndio de força de trabalho humano indiferenciado.

É o tempo de trabalho socialmente necessário que determina a magnitude do valor das mercadorias. É o que permite analisar o trabalho humano de forma homogênea, indiferenciada e fazer o mesmo com o produto do seu trabalho, ou seja, o valor de troca é assim determinado pelo tempo de trabalho socialmente necessário à produção de uma dada mercadoria.

O valor de troca expressa deste modo, trabalho humano indiferenciado, passível de venda, possuidor de valor, pois o valor de troca é a forma historicamente assumida pelo valor na sociedade capitalista, é uma marca característica desta sociedade. O valor é assim expressão do trabalho humano, único capaz de criar valor.

[...] o trabalho, tal como se manifesta nos valores de troca, é trabalho humano geral. Essa abstração de trabalho humano geral existe no trabalho médio que cada indivíduo médio de uma sociedade dada pode realizar: um gasto produtivo determinado de músculos, nervos, cérebro humano etc. (MARX, 2008, p.54).

$\mathrm{Na}$ economia mercantil o valor de troca se apresenta como algo inerente à mercadoria, como se fosse algo natural e não determinado socialmente, não enquanto fruto do trabalho social. É por isso que é importante enfatizarmos que o valor de troca é uma maneira determinada socialmente de expressar o trabalho objetivado, é em si a expressão de uma dada relação social de produção.

O valor de troca não é a materialização de trabalho em geral, existente em todas as formas econômico-sociais, mas é uma forma determinada socialmente, é trabalho que assume a forma da permutabilidade do seu produto. É possível a realização de um trabalho que não resulte na produção de valor, por exemplo, quando é destinado ao consumo individual, para o consumo do seu próprio produtor, mas no capitalismo ele é praticamente inexistente, inexpressivo do ponto de vista da economia.

O valor não é desta forma, igual ao valor de troca, o valor de determinado produto só se expressa no seu valor de troca. O valor de troca é assim, a expressão do valor na troca, mas o valor está dado no momento de sua produção, desde que produzida com a finalidade de ser trocada, ou seja, produzida como uma mercadoria. 
Por outro lado, não há uma completa identidade entre trabalho e valor, assim, trabalho não é necessariamente valor. Valor é expressão social do trabalho, enquanto o trabalho é a substância do valor em determinadas condições histórico-sociais. Nas palavras de Rubin:

O trabalho não pode ser identificado com valor. O trabalho é apenas a substância do valor e, para chegar ao valor no sentido pleno da palavra, o trabalho como substância do valor deve ser tratado em seu vínculo inseparável com 'a forma de valor' (Wertform) social (RUBIN, 1980, p.126).

Se o valor é um fenômeno social, o trabalho que o gera também o é, como afirma Rubin "Segue-se daí que o trabalho abstrato, que cria valor, deve ser entendido como uma categoria social na qual não se pode encontrar um único átomo de matéria" (RUBIN, 1980, p.150).

O trabalho fisiológico em geral não é em si mesmo trabalho abstrato, embora seja um pressuposto do trabalho abstrato. Desta forma, o trabalho igual que se expressa na igualdade do valor, é o trabalho socialmente igual, trabalho igual em sentido social e não natural, já que o valor é uma categoria social e não natural. Não é o trabalho fisiológico que gera valor, mas o trabalho social, "[...] o capital cria uma forma peculiar de riqueza, o valor baseado no trabalho" (ROSDOLSKY, 2001, p.46).

O trabalho abstrato se torna predominante na sociedade capitalista na medida em que a troca se torna a forma social prevalente do processo de produção. É esta a forma que o trabalho assume na sociedade capitalista e os produtos deste trabalho são vistos enquanto possuidores de valor. É por isso que somente o trabalho abstrato produz valor, pois pressupõe determinadas relações de produção entre as pessoas, e não o trabalho no sentido técnico material ou fisiológico.

Enfatizamos aqui, que não podemos nunca perder de vista a forma social do trabalho em Marx. Ele não analisou o trabalho em seu aspecto técnico, mas social, suas diferentes formas sociais, principalmente a que assume na economia capitalista e, para isso, é preciso abstrair o trabalho das suas propriedades técnicas e estudá-lo enquanto categoria social (RUBIN, 1980).

Mesmo as categorias abstratas, válidas para todas as épocas, só atingem a plenitude de seu significado quando analisadas dentro de seu contexto sócio-histórico. É 
desta forma que o trabalho deve ser analisado na sociedade capitalista (ROSDOLSKY, 2001).

$\mathrm{Na}$ sociedade capitalista é através do valor de troca, ou seja, na troca de mercadorias que o trabalho torna-se trabalho social, pois antes da troca constituía-se trabalho particular de indivíduos isolados. É pela consideração do tempo de trabalho socialmente necessário que o trabalho se torna igual, homogêneo, adquirindo assim um caráter social. Aqui o trabalho importa pela sua generalidade, pela sua capacidade de produzir valores de troca. Nas sociedades primitivas o trabalho era social não pela sua generalidade, mas pela sua particularidade ao produzir valores de uso necessários não só a ele (produtor), mas a sociedade na qual ele vive (MARX, 2008).

Como vimos, o trabalho individual só se torna social na troca, desta maneira a transformação do tempo de trabalho individual como tempo de trabalho geral não é pressuposto da troca, mas resultado desta "[...] a realização do tempo de trabalho dos indivíduos como tempos de trabalho geral não é mais que o produto do processo de troca" (MARX, 2008, p.71). O valor é trabalho social, para isso o trabalho individual deve apresentar-se como trabalho social, ou seja, como mercadoria.

O trabalho é a substância social comum a todas as mercadorias, não só trabalho, mas especificamente trabalho social, pois "Aquele que produz um objeto para seu uso pessoal e direto, para consumi-lo, cria um produto, mas não uma mercadoria" (MARX, 1974, p.80). Desta forma, seu trabalho (nada tem a ver com a sociedade) é um trabalho privado, cujos produtos são usufruídos pelo seu próprio produtor. O trabalho produtor de mercadoria é um trabalho social, que está diretamente ligado aos demais produtores de mercadorias, visto que seu produto é destinado à troca e não à utilização enquanto valor de uso.

Mais uma vez é importante insistir em que o valor da mercadoria não é determinado pela quantidade de trabalho objetivado nela, mas pelo tempo de trabalho socialmente necessário para sua produção.

\footnotetext{
Suponhamos que uma mercadoria represente 6 horas de trabalho. Se surgem invenções que permitem produzi-la em 3 horas, cairá também pela metade o valor da mercadoria já produzida. Ela representa agora 3 horas de trabalho social necessário, em vez de 6 como antes. É portanto o quantum de trabalho exigido para sua produção e não sua forma objetivada que determina sua grandeza de valor (MARX, 1985c, p.128).
} 
Nesta passagem Marx deixa claro o caráter estritamente social do valor, este não é produzido por um determinado modelo de trabalho concreto, mas pelo trabalho socialmente necessário.

O trabalho que cria valores de uso é uma condição natural da existência humana, que existe independente das formas de organização social, enquanto o trabalho que cria valores de troca é uma forma social. O trabalho concreto é a fonte das riquezas materiais, assim é o trabalho produtor de valores de uso, enquanto o trabalho abstrato é o produtor do valor de troca, que é a forma social que o trabalho assume no capitalismo.

Só o trabalho possui a capacidade de produzir valor, a matéria natural não tem valor porque não contém trabalho humano, e o valor de troca não necessariamente adota a forma de uma "coisa" palpável. Salientamos o valor da mercadoria força de trabalho que, como no caso dos trabalhadores dos serviços, não produzem um valor de uso separável do seu produtor, consequentemente, também não produzem um valor de troca que seja separável do seu produtor, sua força de trabalho é que possui valor de uso e, como tal, inserido na sociedade capitalista, possui um valor de troca.

A mercadoria é a unidade de valor de uso e valor. Se uma coisa não tem utilidade, tampouco será fonte de valor o tempo de trabalho gasto em produzi-la. Nesse sentido pode se disser que a condição para uma mercadoria ter valor é que tenha alguma utilidade, e há coisas que só manifestam sua utilidade na prestação direta, como no caso dos serviços. Afinal, no que se manifesta o valor do serviço de uma faxineira, senão na prestação da faxina, que é o serviço direto, e não algo que se manifesta de maneira distinta. Esta mesma atividade pode ser realizada pela dona de casa, hipótese na qual não se torna uma mercadoria, mas se for executado por uma empresa que vende faxina, temos um serviço que é uma mercadoria. Mercadoria entendida enquanto possuidora de valor de uso e de troca, cujo valor não se materializa numa coisa toscamente palpável, mas na prestação mesma do serviço.

Trabalho abstrato é o trabalho igual indiferenciado, no qual as diferenças qualitativas se extinguiram, o que sobra é a massa de trabalho humano indiferenciado, ou seja, trabalho abstrato, no qual já não importam as diferenças qualitativas de cada trabalho, aqui o trabalho é considerado somente de forma quantitativa, o que determina 
o valor de troca das mercadorias é a quantidade de trabalho social plasmado nelas. "Como valores de troca de grandeza diferente, apresentam um mais ou menos, maiores ou menores quantias daquele trabalho simples, uniforme, geral abstrato, que constitui a substância do valor de troca" (MARX, 1974, p.143).

Assim, para determinar a grandeza do valor contido nas mercadorias é preciso saber o tempo de trabalho socialmente necessário para sua produção.

\footnotetext{
O tempo de trabalho objetivado nos valores de uso das mercadorias é tão exatamente a substância que os torna valores de troca, e daí mercadorias, como também mede sua grandeza determinada de valor. [...] Como valor de troca, todas as mercadorias são apenas medidas determinadas de tempo de trabalho coagulado (MARX, 1974, p.143).
}

O trabalho materializado na mercadoria, que é a substância do valor de troca, é trabalho médio executado dentro do tempo de trabalho socialmente necessário. "O trabalho de qualquer indivíduo, enquanto se apresente em valores de troca, possui este caráter social de igualdade, e só se apresenta no valor de troca enquanto se relacione como igual com o trabalho de todos os outros indivíduos" (MARX, 1974, p.144 - 145).

Se um trabalho dá origem a um valor de troca é porque é trabalho igual, que pode ser equiparado a qualquer outro. Assim o trabalho do assistente social é trabalho, pois tem um valor de troca5, podendo ser equiparado a todos os demais trabalhos na sociedade capitalista.

\section{A Natureza em Marx}

Para melhor delimitar a categoria trabalho em Marx é preciso esclarecer qual o entendimento do autor em relação à natureza, visto que apresenta o trabalho justamente como a transformação da natureza pelo homem e, posteriormente, formula uma concepção ampliada, mas que não nega a primeira.

De acordo com Schmidt, Marx usa a expressão 'intercâmbio orgânico' entre o homem e a natureza como expressão da estreita ligação entre o homem social e a natureza.

\footnotetext{
${ }^{5} \mathrm{O}$ valor de troca do trabalho do assistente social se manifesta no salário, no caso de ser empregado, ou, nos honorários que recebe nos raros casos em que exerce sua atividade como profissional liberal.
} 
[...] al recíproco entrecruzamiento de naturaleza y sociedad dentro del todo natural, Marx parece haber adoptado finalmente, para la mejor formulación de este hecho, la expresión 'intercambio orgánico' que se mantiene idéntica a todo lo largo de El capital (SCHMIDT, 1976, p.97).

Esta expressão na análise de Marx é empregada para tratar da relação entre o homem social e a natureza, ou seja, o homem inserido na sociedade, na relação desta mesma sociedade com a natureza, e não da relação do homem isoladamente. $\mathrm{O}$ trabalho é, em Marx, o intercâmbio orgânico entre o homem e a natureza, mas o homem aqui, não é o homem entendido individualmente, mas sim social, coletivamente. "Para Marx la naturaleza sólo se manifiesta a través de las formas del trabajo social" (SCHMIDT, 1976, p.54).

O homem é um modo de existência orgânico da natureza e a natureza como existência inorgânica de si mesma. Há uma identidade abstrata do homem com a natureza, o homem é natureza (SCHMIDT, 1976).

Para Marx, a sociedade é constituída pela totalidade das relações de produção e a formação de tais relações é um processo histórico, da mesma forma se constitui a relação da sociedade com a natureza, o que nos permite afirmar que a relação da sociedade com a natureza tem um caráter sócio-histórico.

\footnotetext{
Sin bien Marx define la naturaleza - el material de la actividad humana - como aquello que no es subjetivo, que no se disuelve en los modos de apropiación humana, lo que es directamente no idéntico al hombre, no entiende sin embargo esta realidad exterior al hombre en el sentido de un objetivismo inmediato, y por lo tanto de carácter ontológico. [...] La naturaleza es para Marx un momento de la praxis humana y al mismo tiempo la totalidad de lo que existe (SCHMIDT, 1976, p. 23) [destaque nosso].
}

Para Marx o homem é diferente da natureza, é um ser social, mas, ao mesmo tempo, não deixa de ser natural, de pertencer à natureza. É justamente este entendimento de Marx que nos permite afirmar que a natureza é a totalidade do que existe e, desta forma, o homem faz parte desta mesma natureza, como afirma Vázquez.

Há unidade do homem e da natureza: a) na medida em que a natureza é homem (natureza humanizada) e b) na medida em que, como ser natural humano, é também natureza. [...] Nem a natureza é separável do homem, e por isso, Marx fala da 'realidade social da natureza', nem as ciências naturais podem ser separadas da ciência do homem (VÁZQUEZ, 2007, p.131). 
A natureza é a totalidade do real, o conjunto da realidade, da qual o homem é integrante, assim como tudo por ele construído.

O trabalho é a forma humana de agir na natureza, por meio do trabalho o homem se humaniza. Isso não significa que deixou de ser natureza, mas tornou-se homem. Como evidenciamos, o homem é produto do trabalho, é o trabalho que humaniza o homem e é também por meio do trabalho que o homem humaniza a natureza.

O homem é o único ser que se relaciona com a natureza através de uma mediação, o trabalho, e consequentemente o intercâmbio orgânico entre o homem e a natureza não é só a transformação da natureza. O homem, neste processo, impõe a sua vontade, de acordo com os conhecimentos que domina, "materializa" ou expressa algo já previamente idealizado ou imaginado.

Os animais também transformam a natureza, como claramente explica Marx na conhecida passagem na qual demonstra que tanto $o$ arquiteto quanto a abelha promovem uma transformação da natureza e que, nem por isso, podemos afirmar que as abelhas trabalhem.

[...] a influência duradoura dos animais sobre a natureza que os rodeia é inteiramente involuntária e constitui, no que se refere aos animais, um fato acidental. Mas quanto mais os homens se afastam dos animais, mais sua influência sobre a natureza adquire um caráter de ação intencional e planejada, cujo fim é alcançar objetivos projetados de antemão (ENGELS, s/d, p. 276).

É neste sentido que Marx afirma que o trabalho é algo que não se pode suprimir, independente da forma de vida, eterno intercâmbio Homem/Natureza, para produção de valores de uso. Esta relação de dependência do homem com a natureza sempre vai existir, nas diferentes formações sociais, mas de formas diferentes, ou seja, o homem precisa se apropriar da natureza para produzir os bens necessários a sua reprodução, mas esta apropriação ocorre de formas diversas, mudam de acordo com as transformações sofridas pela própria sociedade. Ou, como diz Marx, o que difere uma sociedade da outra não é o que se produz, mas como se produz, ou seja, são as relações sociais que nos permitem diferenciar os diversos modos de produção. Não podemos assim, ignorar o desenvolvimento das forças produtivas. 
Salientamos que, para Marx, o homem faz parte da natureza, daí poder concluir que mesmo algumas atividades que não transformam diretamente a natureza6, são trabalho, pois transformam o próprio homem que é natureza.

O trabalho é justamente aquilo que humaniza o homem, que o distingue da muda natureza, mas, nem por isso, o homem deixa de ser parte da natureza. A natureza existe independente do homem, mas a sociedade não se sustenta sem a natureza, até porque, é parte integrante desta. A definição do homem como ser natural indica a dependência do homem em relação à natureza exterior. O homem faz parte da natureza, ou, como afirma Engels:

[...] nós, por nossa carne, nosso sangue e nosso cérebro, pertencemos à natureza, encontramo-nos em seu seio, e todo o nosso domínio sobre ela consiste em que, diferentemente dos demais seres, somos capazes de conhecer suas leis e aplicá-las de maneira adequada (ENGELS, s/d, p. 277).

O homem somente se entende como integrante da natureza quando se torna um ser social, mas, ao tornar-se um ser social, não deixa de ser um ser natural "O homem, no entanto, não é apenas ser natural, mas ser natural humano, isto é, um ser que é para si próprio e, por isso, ser genérico [...]" (MARX, 1974, p.47). O homem faz parte da natureza, mas, ao mesmo tempo, é algo distinto dela, em contraposição ao animal que se confunde com a própria natureza. A natureza é o corpo inorgânico do homem. A natureza é força produtiva em potencial, "[...] el hombre mismo es, para sí mismo y para otro hombre, además de una fuerza productiva social, también una fuerza productiva natural" (PRESTIPINO, 1977, p.162).

Esta aparente contradição entre o homem natural e o social resolve-se com o surgimento da sociedade.

A essência humana da natureza não existe senão para o homem social [...]. A sociedade é, pois, a plena unidade essencial do homem com a natureza, a verdadeira ressurreição da natureza, o naturalismo acabado do homem e o humanismo acabado da natureza (MARX, 1974, p.15).

Com o desenvolvimento da grande indústria capitalista o homem - no sentido de sua força de trabalho física individual - deixa de ser o principal agente da produção. É a

\footnotetext{
${ }^{6}$ Natureza, entendida aqui em sentido restrito, como aquilo exterior ao homem.
} 
indústria a que transforma cada vez mais o papel do trabalhador no de supervisor e regulador. Neste contexto, o que se apresenta como fundamental para a produção e a riqueza não é o trabalho imediato do homem, nem o seu tempo de trabalho individual, mas a apropriação de sua força de trabalho em sentido geral, pois o que importa é sua existência como corpo social, o desenvolvimento do individuo social e não do indivíduo entendido de forma isolada. Mais uma vez Marx deixa claro que, para análise do trabalho na sociedade industrial, o indivíduo não pode ser entendido de forma isolada, mas enquanto coletividade, como um corpo social.

“[...] O trabalhador já não introduz a coisa natural modificada, como elo intermediário, entre o objeto e ele mesmo, mas insere o processo natural, transformado em processo industrial, como meio entre si mesmo e a natureza inorgânica, à qual domina. Apresenta-se ao lado do processo de produção, em vez de ser seu agente principal. Nessa transformação, o que aparece como pilar fundamental da produção e da riqueza não são nem o trabalho imediato executado pelo homem nem o tempo que este trabalha, mas sim sua força produtiva geral, sua compreensão da natureza e seu domínio sobre ela graças à sua existência como corpo social; em uma palavra, o desenvolvimento do indivíduo social" (MARX apud ROSDOLSKY, 2001, p.354).

Tampouco podemos considerar o processo de trabalho independente de toda e qualquer forma histórica, como se fosse algo imutável ao longo da história, isso seria negar toda a historicidade presente e tão cara a análise de Marx do desenvolvimento do modo de produção. Assim, consequentemente, a forma de interação do homem com a natureza sofre alterações ao longo da história, que não podemos ignorar. A produção se dá dentro de determinada forma social.

Fica evidente que o entendimento marxista de natureza é idêntico ao de realidade em seu conjunto. "Así como la naturaleza no es separable del hombre, inversamente tampoco el hombre y sus producciones espirituales son separables de la naturaleza" (SCHMIDT, 1976, p.27).

O animal "produz" somente para atender necessidades físicas, enquanto o homem produz independente desta necessidade, na verdade, o homem só produz verdadeiramente quando está livre da necessidade física. No entanto, no homem, mesmo a necessidade de se alimentar é mediada socialmente. 
[...] o trabalho não pode ser compreendido como uma atividade dirigia para a satisfação de necessidades eternas e imutáveis. As necessidades que efetivamente determinam a produção não são as necessidades estritamente naturais, mas sim aquelas suscitadas pela própria produção (GOMEZ, 2004, p.29).

Tal afirmação relativiza à compreensão de Lessa, que insiste apenas no aspecto da eterna necessidade "do homem em produzir seus meios de subsistência". De acordo com Gomez, esta necessidade é mediada historicamente, ou seja, o homem sempre terá a necessidade de produzir seus meios de subsistência, no entanto, a forma, o modo de produção varia historicamente, ou seja, o trabalho é determinado historicamente.

\begin{abstract}
Enquanto o homem existir ele terá que dedicar parte do tempo da sociedade para se apropriar dos objetos da natureza e de transforma-los em objetos de uso humano através do trabalho. Essa é uma necessidade insuprimível da realidade humana. No entanto, é importante observar que se é verdade que o homem jamais poderá deixar de se apropriar dos objetos da natureza por intermédio do trabalho, o modo como ele realiza essa apropriação é historicamente cambiante. A compreensão do modo como os homens se apropriam e transformam a natureza está indissociavelmente ligado às formas como os homens se relacionam entre si e ao desenvolvimento das forças produtivas da sociedade (GOMEZ, 2004, p.38).
\end{abstract}

Evidenciamos que o homem é um ser natural e que, com o desenvolvimento histórico, tornou-se social, sem com isso deixar de ser natural, ou seja, o homem social é um ser natural, "[...] o homem - é natureza [...]" (MARX, 1974, p.15).

A força de trabalho é, antes de tudo, matéria natural transformada em organismo humano, como afirma Marx "El hombre mismo, considerado como mera existencia y fuerza laboral, es un objeto de la naturaleza, una cosa, aunque sea una cosa viva y autoconsciente, y el trabajo mismo es expresión en las cosas de aquella fuerza" (apud SCHMIDT, 1976, p.73).

A teoria marxista é essencialmente histórica, e é justamente para evidenciar esta característica da teoria marxista que Lukács, afirma que a própria

[...] naturaleza es una categoría social. Lo que vale como naturaleza en un determinado grado de desarrollo social, la estructura de la relación entre hombre y naturaleza y el modo en que el hombre se mide con ella, por lo tanto el sentido que la naturaleza debe tener en vinculación con su forma y su contenido, y su objetividad, es siempre algo socialmente condicionado (apud SCHMIDT, 1976, p.198) [destaque nosso]. 
Como podemos perceber nesta citação de Lukács, o que se entende por natureza em dado momento é algo socialmente determinado, da mesma forma é a relação entre o homem e a natureza.

O homem é parte da natureza, é o produto de uma longa evolução biológica que, em certo ponto, inicia uma nova forma específica de desenvolvimento, a história humana, caracterizada por uma maneira de agir autônoma, autorreflexiva e criativa. O homem é, portanto, essencialmente um ser que tanto transforma a natureza como cria a si mesmo, adquire um controle cada vez maior sobre as forças naturais cegas e produz um novo ambiente natural humanizado. Por outro lado, produz grande variedade de capacidades e necessidades, que se tornam então o ponto de partida de novo autodesenvolvimento.

A força de trabalho é uma fonte geradora de riqueza para o capital, assim, não só a exploração da natureza é fonte de riqueza para o capital, mas a força de trabalho explorada, na condição de trabalho assalariado, é geradora de riqueza para o capital. O capital é um sistema de exploração geral das propriedades da natureza e do homem, como podemos observar na formas de ampliação da extração da mais-valia, que tanto na sua forma relativa quanto na absoluta, pode ser aplicada a todo e qualquer trabalho assalariado sob o jugo do capital.

O capital promove o desenvolvimento necessário às forças produtivas sociais, de modo a tornar possível a produção de um trabalho excedente sem precedentes na história da humanidade, o que cria as condições necessárias para o fim da exploração do homem pelo homem, pois a reprodução exige um tempo de trabalho menor para toda a sociedade, ou seja, cada vez uma quantidade menor de trabalho é requerida para promover a reprodução da sociedade.

O desenvolvimento das forças produtivas promovido pelo capital é premissa para o surgimento de um novo modo de produção que permitirá o desenvolvimento pleno das potencialidades humanas, que não estarão mais limitadas pelos interesses de autovalorização do capital, estarão voltadas ao desenvolvimento da humanidade.

Neste novo modo de produção o homem finalmente terá conquistado sua liberdade, entendida enquanto fim da exploração do homem pelo homem, e no qual se reduz o trabalho ao mínimo necessário visto que será explorada toda a capacidade das forças produtivas, exatamente o inverso do que ocorre atualmente, pois o capitalismo, 
apesar de contribuir para o desenvolvimento de tais forças produtivas, também limita sua utilização conforme sua necessidade de reprodução, desconsiderando as necessidades de reprodução dos seres humanos. Prova disso é que, em momentos de crise, a produção é reduzida com vistas a garantir a lucratividade do capital, mesmo que tal redução prejudique a reprodução dos seres humanos, pois o que importa no capitalismo é a sua reprodução e não a reprodução da sociedade. O capitalismo cria as condições necessárias à sua superação, em direção a uma sociedade sem classes.

A forma assalariada de exploração, como forma de acumulação da riqueza, cria as próprias condições para sua superação, a exploração exaustiva do trabalhador atualmente é uma mesquinhez do capitalismo, que poderia produzir muito mais caso utilizasse todas as potencialidades das forças produtivas, ou seja, atualmente se produz menos do que se poderia produzir, pois a produção é comandada pelos interesses de reprodução do capital.

Assim como o capitalismo promove o desenvolvimento das forças produtivas, restringe seu uso quando the é conveniente. Com o fim do trabalho assalariado os trabalhadores deixaram de ser "apêndice" do processo de trabalho, para serem "[...] verdadeiros dirigentes do processo de produção" (ROSDOLSKY, 2001, p. 356). É importante observar que o trabalho não irá desaparecer, visto que é condição natural da vida humana, desaparecerá a exploração do homem pelo homem, que se manifesta na apropriação do trabalho alheio.

\section{Referências}

ENGELS, F. O papel desempenhado pelo trabalho na transição do macaco ao homem. In: MARX, K; ENGELS, F. Obras Escolhidas. São Paulo: Alfa-Omega, s/d. v.2, p.269-280.

GOMEZ, A. V. A dialética da natureza de Marx: os antagonismos entre capital e natureza. 2004. Dissertação (Mestrado em Filosofia) - Pontifícia Universidade Católica do Rio de Janeiro, Rio de Janeiro.

MARX, K. O Capital: crítica da economia política. Tradução por Regis Barbosa e Flávio R. Kothe. São Paulo: Abril Cultural, 1985a. Livro 1, v.1, t.1. (Os economistas).

MARX, K. O Capital: crítica da economia política. Tradução por Regis Barbosa e Flávio R. Kothe. São Paulo: Abril Cultural, 1985c. Livro 1, v. 1, t. 2 (Os economistas). 
MARX, K. Manuscritos econômico-filosóficos e outros textos escolhidos. São Paulo: Abril Cultural, 1974. (Os Pensadores).

MARX, K. 1818-1883. Contribuição à critica da economia política. Tradução por Florestan Fernandes. 2.ed. São Paulo: Expressão Popular, 2008

PRESTIPINO, G. El pensamiento filosófico de Engels: naturaleza y sociedad en la perspectiva teórica marxista. Madrid: Siglo Veintiuno, 1977.

ROSDOLSKY, R. Gênese e estrutura de o Capital de Karl Marx. Rio de Janeiro: Eduerj/Contraponto, 2001.

RUBIN, I.I. A teoria marxista do valor. São Paulo: Brasiliense, 1980.

SCHMIDT, A. El concepto de naturaleza en Marx. Madrid: Siglo Veitiuno, 1976.

VÁZQUEZ, A.S. Filosofia da práxis. Tradução por: Maria Ercarnación Moya. São Paulo: Expressão Popular, 2007. 